\title{
Profits Management for Reverse Supply Chain with Supply Disruption
}

\author{
Gu Qiaolun ${ }^{1 *}$ Gao Tiegang ${ }^{2}$ \\ ${ }^{1}$ School of Information Technology Engineering, Tianjin University of Technology and Education, \\ Tianjin, P.R. China, 300222 \\ ${ }^{2}$ College of Software, Nankai University, \\ Tianjin, P.R. China, 300071 \\ *Corresponding author's Email:tjguqiaolun@sohu.com
}

\begin{abstract}
In reverse supply chain under our study, there are four supply disruptions. As the source of the reverse supply chain, the supply disruption of used-products between end-consumers and collector will largely affect the profits of the reverse supply chain. In order to manage the profits of the reverse supply chain, we give an expanded stock-flow diagram with this supply disruption of the reverse supply chain by using system dynamics methodology, show the simulation results of collector's profit, disassembly center's profit, remanufacturer's profit and the mean of their profits under different disruption periods. By analyzing the simulation results, we present a strategy to ensure the members positive profits. The strategy is adding another channel of purchasing used-products for the collector. We show the simulation results of the members profits and their mean after using the strategy, and give the suitable range of purchase quantity of used-products for the strategy.
\end{abstract}

Keywords: Supply disruption; Profit; Management; Reverse supply chain

\section{Introduction}

The reverse supply chain under our study includes three members: collector, disassembly center and remanufacturer. The collector will collect the used products from the end-consumers and sell them to the disassembly center. The disassembly center will reprocess the used-products and sell the key remanufactured part to the remanufacturer. The remanufacturer will produce remanufactured product which contains the key remanufactured part and sell them to the consumer market.

There are four supply disruptions in this reverse supply chain: supply disruption of used-products between end-consumers and collector, supply disruption of usedproducts between collector and disassembly center, supply disruption of key remanufactured parts between disassembly center and remanufacturer, and supply disruption of remanufactured products between remanufacturer and consumer market. Each supply disruption has specific impact on the members profits of the reverse supply chain and need special method to avoid the disruption risk and manage the members profits. With regard to the last three supply disruptions, we have given the simulation analysis and strategies. For example, as for the supply disruption of key remanufactured parts, $\mathrm{Gu}$ and Gao present a system dynamics model to simulate the remanufacturers profit, and choose a strategy to ensure the remanufacture can get profit when the supply disruption lasts for a long time [1]. Therefore, in this paper, we will study the first supply disruption. The goal of our study is to simulate the supply disruption and analyze the impacts of supply disruption on the profits of the reverse supply chain by using system dynamics methodology. By analyzing the simulation results, we will present a strat- 
egy to ensure the members positive profits.

The remainder of the paper is organized by following sections: section 2 will show the literatures related to our study. Section 3 will give stock-flow diagram of the reverse supply with supply disruption of usedproducts between end-consumers and collector. Section 4 will present the simulation results and analyze the impacts of supply disruption on profits of reverse supply chain. Section 5 will give a strategy to ensure the members positive profits, show the simulation results of the members profits after using the strategy and present the suitable range of purchase quantity of used-products. Section 6 will summarize the analysis results and give the further study directions.

\section{Literature Review}

The research results related to our study focus on supply disruption management and system dynamics application in reverse supply chain.

For the supply disruption management, Shao examines demand-side reactive strategies for supply disruption in a multiple assemble-to-order system. Two different supply disruption situations are examined: disruption of the low-value component and disruption of the high-value component. He proposes and compares the performance of four reactive strategies for managing supply disruptions [2]. Sarkar and Mohapatra consider the risks of supply disruption due to occurrence of super, semi-super, and unique events in order to formulate a model to determine the optimal size of supply base [3]. Hou, Zeng, and Zhao study a buyback contract between a buyer and a backup supplier when the buyers main supplier experiences disruptions [4]. Xanthopoulos, Vlachos and Iakovou propose generic single period (newsvendor-type) inventory models for capturing the trade-off between inventory policies and disruption risks in a dual-sourcing supply chain network both unconstrained and under service level constraints, where both supply channels are susceptible to disruption risks [5]. Huang, Yang, Zhang and Liu build two models for a supply chain under two circumstances of supply disruptions by using the methodology of system dynamics modeling [6].

About the System Dynamics application in reverse supply chain, Gu and Gao present the model and simulation for disassembly plan in the reverse supply chain by system dynamics methodology. Their goal is to make a decision for the disassembly plan via analyzing the simulation results in order to lower the inventory levels and ensure the service levels by a small- er disassembly rate [7]. Da, Sun and Zhou analyze the behavior of the reverse supply chain through a dynamic simulation model based on the principles of the system dynamics methodology considering environmental protection policies and capacity planning strategies of remanufacturing capacity simultaneously [8]. Gu and Gao present a system dynamics model and show the change of the inventories, the service levels, and the profits of the reverse supply chain with and without RFID-EPC [9]. Gu and Gao propose a system dynamics model to examine the long-term behavior of R/M integrated supply chain with reusing, remanufacturing and recycling. In their study, the optimal decision sets of the remanufacturing ratio and the setup period of remanufacturing are given, and the joint decisions of all members of $\mathrm{R} / \mathrm{M}$ integrated supply chain under the optimal decision set are presented by the simulation results [10]. Georgiadis and Besiou examine the impact of ecological motivation and technological innovations on the long-term behavior of a closed-loop supply chain with recycling activities using system dynamics methodology. The system they study includes the activities: procurement of natural resources (non-renewable materials), production, distribution, product use, and collection of used product$\mathrm{s}$, dismantling, sorting, recycling and disposal. There are two echelons (producer and distributor) in the forward supply chain, and the reuse activity is recycling in the reverse channel [11].

\section{Model}

System Dynamics (SD) methodology is a modeling and simulation technique specifically designed for long-term, chronic, dynamic management problems. Vensim ${ }^{\circledR} 5.10$ is a visual modeling tool that can be used to conceptualize, document, simulate, analyze, and optimize models of dynamic systems. In this section, we will use Vensim ${ }^{\circledR} 5.10$ to develop the stockflow diagram of the reverse supply chain, simulate and analyze the simulation results.

\subsection{Stock-flow diagram with supply disruption of the reverse supply chain}

Vensim ${ }^{\circledR} 5.10$ provides a simple and flexible way of building simulation models from stock and flow diagrams that captures the model structure and the interrelationships among the variables. The stock-flow diagram of the reverse supply chain with supply disruption of used-products between end-consumers and collector developed by using theVensim ${ }^{\circledR} 5.10$ software is shown in Figure 1. 
The stock-flow diagram of the reverse supply chain with supply disruption in Figure 1 is expanded from the stock-flow diagram of [9] which did not concern the disruption risk. Comparing the stock-flow diagram with supply disruption in Figure1 with the stockflow diagram of [9], we have the following changes: add a shadow variable Time to describe the disruption periods (see the dashed rectangle) in order to simulate and analyze the impacts of different disruption periods; change the equation of collecting rate; add three variables collector's profit, disassembly center's profit and remanufacturer's profit.

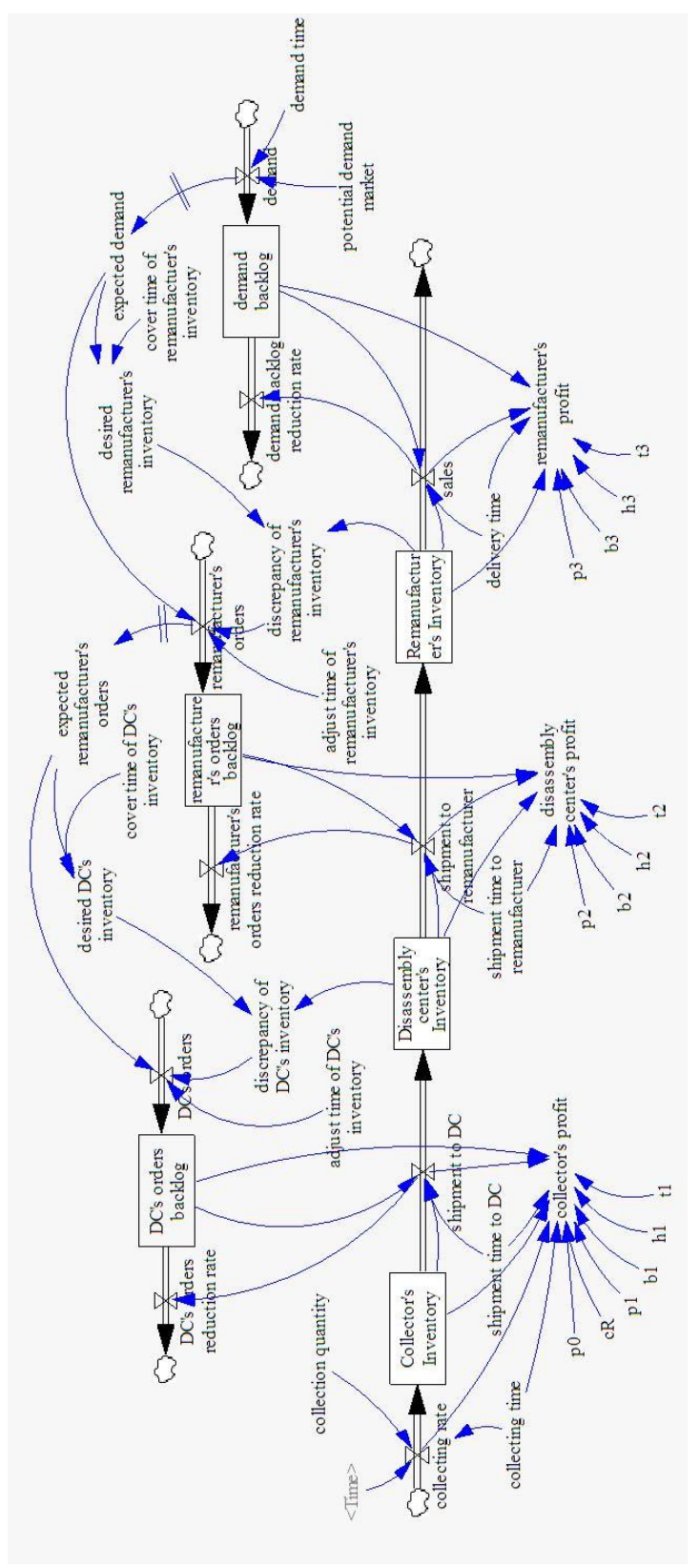

Figure 1 Stock-flow diagram of the reverse supply chain with supply disruption diagram are the same as that in [9]. Herein, we only give the changes of the variables and the equations.

\subsection{Changed and added Equations}

The changed equation is collecting rate:

collecting rate $=\left\{\begin{array}{l}\text { collection quantity/collecting time }, \\ \text { Time } \leq m, \text { Time }>n \\ 0, m \leq \text { Time } \leq n\end{array}\right.$

where, $m$ and $n$ are the simulation periods. The added equations are collector's profit, disassembly center's profit and remanufacturer's profit.

collector's profit $=(p 1-t 1) \cdot$ shipment to DC. shipment time to $D C-(p 0+c R) \cdot$ collecting rate . collecting time $-h 1 \cdot$ Collector's Inventory $-b 1$. $D C^{\prime}$ s orders backlog

where $p l$ is the unit sale price when the collector sells a collected used-product to the disassembly center. $t 1$ is the unit transport cost when the collector transport$\mathrm{s}$ a collected used-product to the disassembly center. $p 0$ is the unit collecting price when the collector collects a used-product from the end-customer. $c R$ is the unit monitoring cost when the collector monitors the state of a used-product waiting for being collected by using RFID-EPC. $h l$ is the unit holding cost of a usedproduct in collectors inventory. $b 1$ is the unit penalty if the DC's orders backlog cant be satisfied.

disassembly center's profit $=(p 2-t 2) \cdot$ shipment to remanufacturer shipment time to remanufact urer $-h 2 \cdot$ Disassembly center's Inventory $-b 2 \cdot r e$ manufacturer's orders backlog

where $p 2$ is the unit sale price when the disassembly center sells a key part to the remanufacturer. $t 2$ is the unit transport cost when the disassembly center transports a key part to the remanufacturer. $h 2$ is the unit holding cost of a key part in disassembly centers inventory. $b 2$ is the unit penalty if the remanufacturer's orders backlog cant be satisfied.

remanufacturer's profit $=(p 3-t 3) \cdot$ sales $\cdot$ delivery time $-h 3 \cdot$ Remanufacturer's Inventory $-b 3 \cdot$ demand backlog

The equations and constants used in this stock-flow 
where $p 3$ is the unit sale price when the remanufacturer sells a remanufactured product to the consumer market. $t 3$ is the unit transport cost when the remanufacturer transports a remanufactured product to the end-customer. $h 3$ is the unit holding cost of a remanufactured product in remanufacturer's inventory. $b 3$ is the unit profit loss if the demand backlog can't be satisfied.

\section{Simulation Results of Profits}

For our simulation, the values used in equations (1), (2), (3) and (4) are listed below:

In equation (1), $m=10$ and $n=10,11,12,13,14,15$ and 16 respectively. In the case of $m=10$ and $n=10$, there is no supply disruption. In the case of $m=10$ and $n=11$, the supply disruption lasts for one period. In the case of $m=10$ and $n=12$, the supply disruption lasts for two periods, and so on.

In equation (2), the unit collecting price of a usedproduct when the collector collects a used-product from the end-consumer is $p O=20$, the unit monitoring cost is $c R=5$, the unit sale price of a collected used-product when the collector sells a used-product to the disassembly center is $p l=400$, the unit transport cost of a collected used-product from the collector to the disassembly center is $m t 1=1$, the unit holding cost of a used-product in collectors inventory is $h l=10$ and the unit penalty is $b l=40$.

In equation (3), the unit sale price of a key remanufactured part when the disassembly center sells it to the remanufacturer is $p 2=500$, the unit transport cost of a remanufactured part from the disassembly center to the remanufacturer is $t 2=1.5$, the unit holding cost is $h 2=15$ and the unit penalty is $b 2=50$.

In equation (4), the unit sale price of a remanufactured product when the remanufacturer sells it to the consumer market is $p 3=800$, the unit transport cost of a remanufactured product from the remanufacturer to the consumer market is $t 3=2$, the unit holding cost is $h 3=20$ and the unit penalty is $b 3=100$.

\subsection{Impacts of supply disruption on profit}

Based on the above values, the simulation results of collector's profit, disassembly center's profit and remanufacturer's profit are shown in the following Figure 2, Figure 3 and Figure 4 respectively. Herein, withdisruption 0 means there is no supply disruption, namely, $m=10$ and $n=10$. withdisruptionl means the supply disruption lasts for one period, and so on.

From the simulation results in Figure 2, the findings are as follows:

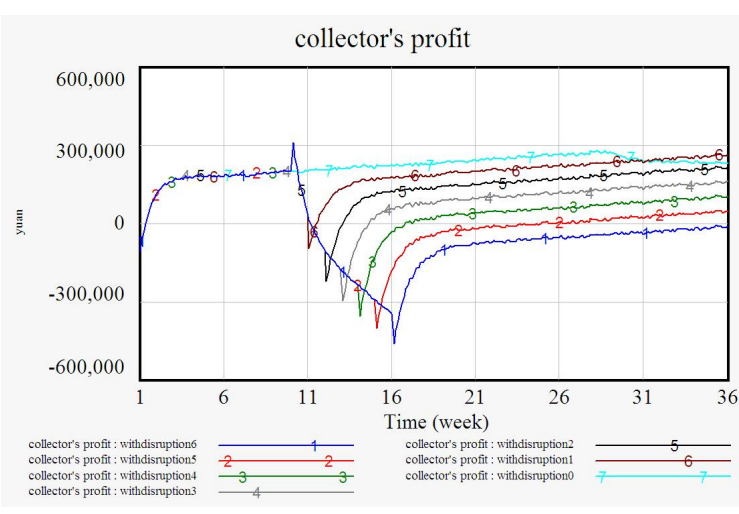

Figure 2 Collectors profits under different disruption periods

The collector's profit will increase quickly at the beginning of the supply disruption, and then decrease till the end of the supply disruption. The reason of the quick increase at the beginning is the decrease of the collecting cost because the collecting rate is zero and the shipment to $D C$ is not affected at that time. However, during the disruption periods after the beginning, the shipment to $D C$ will be affected by the collecting rate, and the collector's profit will decrease.

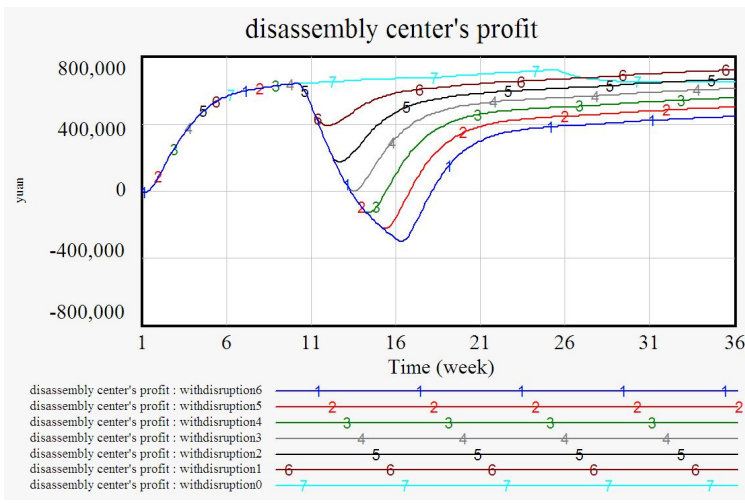

Figure 3 Disassembly centers profits under different disruption periods

If the supply disruption is ended, the collector's profit will increase again. If the supply disruption periods are smaller than or equal to 5, the collector's profit become more than zero again from some period. But, if the supply disruption lasts for six periods, the collector's profit cannot be more than zero again even though it increases after the supply disruption (see withdisruption6).

The decreasing degree of the collector's profit will larger when the disruption periods increase.

So, from the collectors perspective, he should do his best to end the supply disruption as soon as possible, 
especially, the supply disruption periods must not exceed 5.

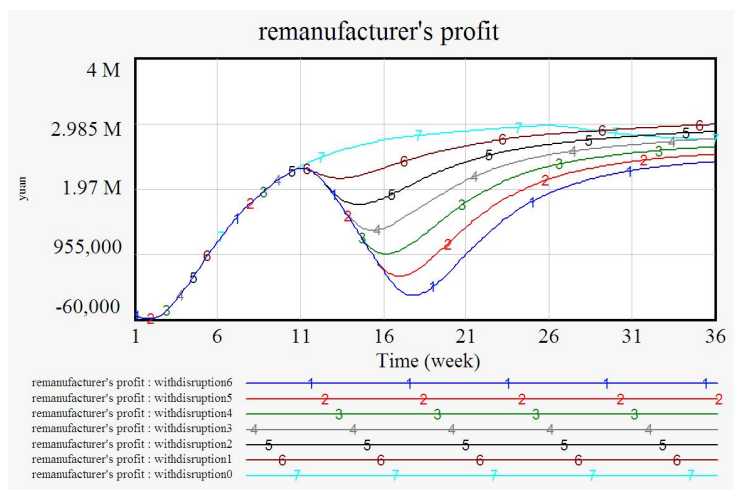

Figure 4 Remanufacturers profits under different disruption periods

From the simulation results in Figure 3 and Figure 4, the findings are as follows:

The disassembly center's profit (remanufacturer's profit) will decrease when a supply disruption occurs till the end of the supply disruption.

If the supply disruption is ended, the disassembly center's profit (remanufacturer's profit) will continue to decrease some periods and then increase again.

If the supply disruption periods are not larger than 6 , the disassembly center's profit (remanufacturer's profit) can become more than zero again from some period.

The decreasing degree of the disassembly center's profit (remanufacturer's profit) will larger when the disruption periods increase.

\subsection{Impacts of supply disruption on the mean of profit}

Its obviously from the above Figure 2 to Figure 4 that in some periods the collector's profit, the disassembly center's profit and the remanufacturer's profit are negative. Therefore, its necessary to investigate the average values of their profits under different supply disruption periods. We show the mean of profit under different supply disruption periods for each reverse supply chain member in Figure 5.

Figure 5 shows that: The mean of the collector's profit will reduce when the supply disruption lasts more periods. Especially, if the supply disruption lasts for 5 or 6 periods, the mean of the collector's profit will be approximate or smaller than zero. The mean of the disassembly center's profit (remanufacturer's profit) are positive even though it will reduce when the supply disruption lasts more periods. Namely, the collector should ensure the supply disruption lasts no more

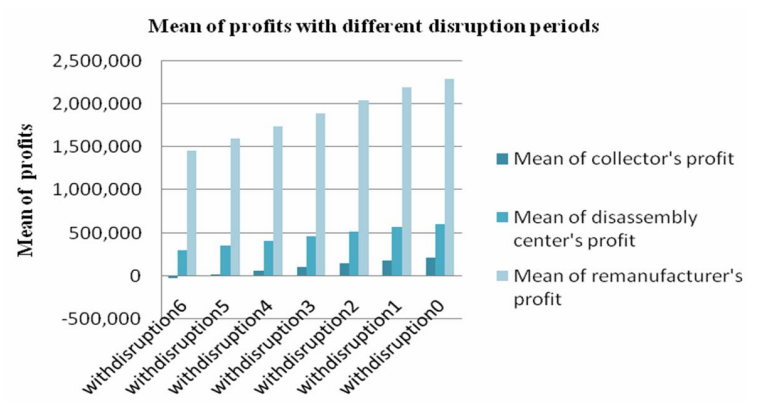

Figure 5 Mean of profits under different disruption periods

than 5 periods in order to get positive profit, and this will ensure positive profit for the other members of the reverse supply chain during the simulation period$\mathrm{s}$ (36 periods). This analysis result partially owes to the disassembly center's inventory and remanufacturers inventory.

At the same time, another problem is how the collector can ensure the supply disruption lasts no more than 5 periods? Of course, its OK if the collector can control the supply disruption of the used-products and can end it in time. However, facing the supply disruption of used-products, if the collector cant control and end it, namely, he cant get positive profit, what can he do? Next, we will give a strategy to solve this problem.

\section{Strategy and Simulation Results of Profits}

\subsection{Strategy}

When the collector can not control the supply disruption of the used-products to ensure the supply disruption lasts no more than 5 periods, he can obtain the sources of used-products via purchasing the usedproducts from other areas in order to get positive profit when the supply disruption lasts more than 5 periods. Therefore, our strategy is adding another channel of the source of used-products for the collector as shown in Figure 6.

In Figure 6, we add the following elements:

purchasing rate: the rate of purchasing used-products from other areas. [Units: piece/week]

purchasing time: [Units: week]

purchase quantity: [Units: piece]

purchasep: unit price of purchasing a used-product from another areas. [Units: yuan]

The added and changed equations are listed below. 
changed to equations (6) and (7) respectively.

purchasing rate $=\left\{\begin{array}{l}\text { purchase quantity } / \text { purchase } \\ \text { time }, k<\text { Time }<l \\ 0, \text { Time } \leq k, \text { Time } \geq l\end{array}\right.$

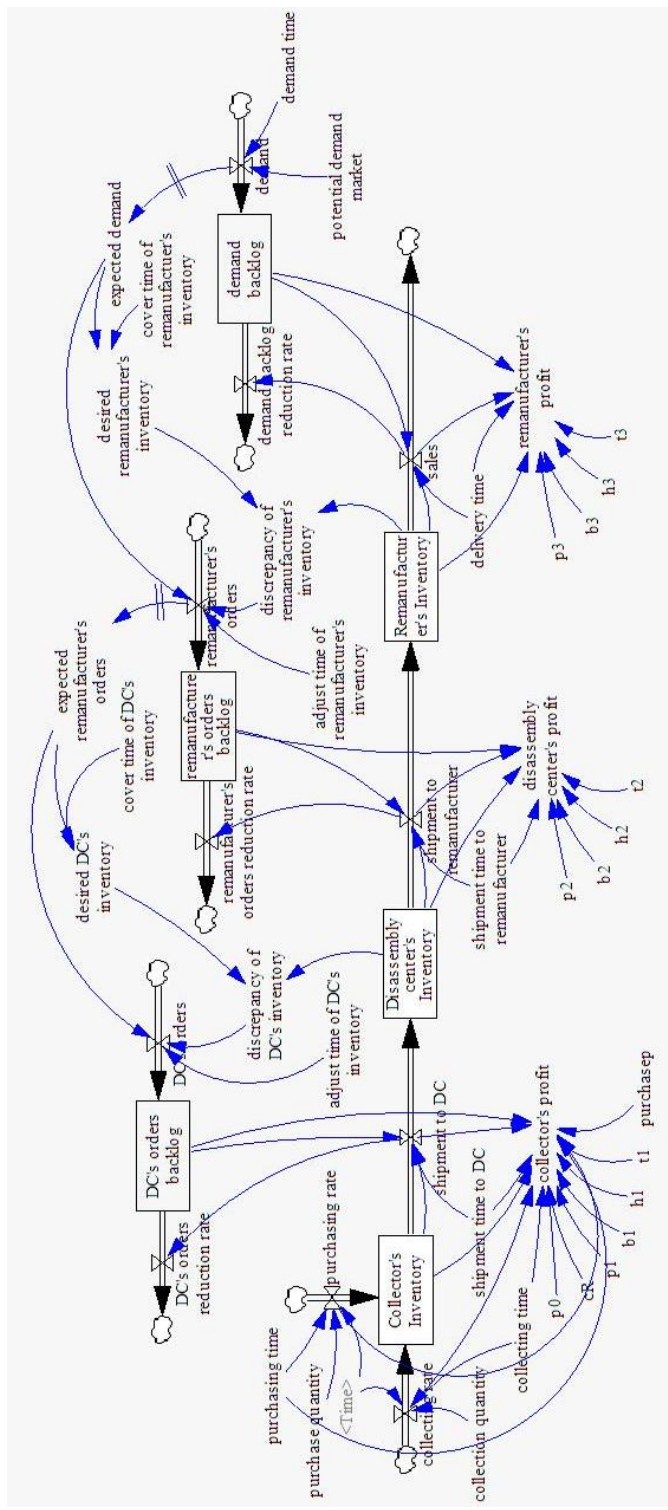

Figure 6 Added elements in partial stock-flow diagram of the reverse supply chain with supply disruption

Here, $k$ and $l$ are the simulation periods, and $k<=$ $l$. Equation (5) means the purchasing rate will be purchase quantity/purchasing time between the $k^{\text {th }}$ period and the $l^{\text {th }}$ period, namely, the collector will purchase used-products from other areas during the $k^{\text {th }}$ period and the $l^{\text {th }}$ period, and the collecting rate will be zero at the same time.

Because of the adding elements, the equations of collector's profit and collector's inventory have been collector's profit $=(p 1-t 1) \cdot$ shipment to $D C \cdot$ shi pment time to $D C-(p 0+c R) \cdot$ collecting rate $\cdot$ col lecting time $-h 1 \cdot$ Collector's Inventory $-b 1 \cdot D C^{\prime} s$ orders backlog - purchasep $\cdot$ purchasing rate $\cdot$ purc hasing time

where, purchasep $\cdot$ purchasingrate $\cdot$ purchasingtime mean$\mathrm{s}$ the purchase cost when the collector purchases the used-products from other areas.

$$
\begin{aligned}
& \text { Collector's Inventory }=I N T E G(\text { collecting rate }+ \\
& \text { purchasing rate }- \text { shipment to } D C)
\end{aligned}
$$

where, purchasing rate is the rate of obtaining the used-product from other areas.

\subsection{Simulation results of profits by using the $s$ - trategy}

For the simulation in this subsection, the values used in equations (5) and (6) are listed below.

In equation (5), if the supply disruption lasts no more than 4 periods, $k=10$ and $l=10$, it means the collector neednt purchase used-products from other areas. If the supply disruption lasts for 5 periods, $k=13$ and $l=15$, it means the collector will purchase used-products from other areas during the $14^{\text {th }}$ period and the $15^{\text {th }}$ period. If the supply disruption lasts for 6 periods, $k=13$ and $l=16$, it means the collector will purchase used-products from other areas during the $16^{\text {th }}$ period and the $16^{\text {th }}$ period.

In equation (6), purchasing time is 4 weeks, and the unit purchase cost for a used-product purchasep is 25yuan. Here, the purchase price purchasep is larger than the collecting price $p 0$ ( $p 0=20$ yuan). About the purchase quantity, we will give the value according to the simulation situation.

\subsubsection{Impacts of supply disruption on profit by using the strategy}

Herein, purchase quantity is 2000 [Units: piece]. Based on the above values, the simulation results of collector's profit, disassembly center's profit and remanufacturer's profit under the strategy are shown in the following Figure 7, Figure 8 and Figure 9 respectively.

Comparing the simulation results in Figure 7 with the simulation results in Figure 2, we can find: 
When the supply disruption lasts for 5 periods (or 6 period) and the collector adopts the strategy, namely, the collector will purchase used-products from the $14^{\text {th }}$ period to the $15^{\text {th }}$ period (or to the $16^{\text {th }}$ period), the collector's profit(see the lines marked with 2 or 1 ) will increase and will be larger than that of no strategy in Figure 2.

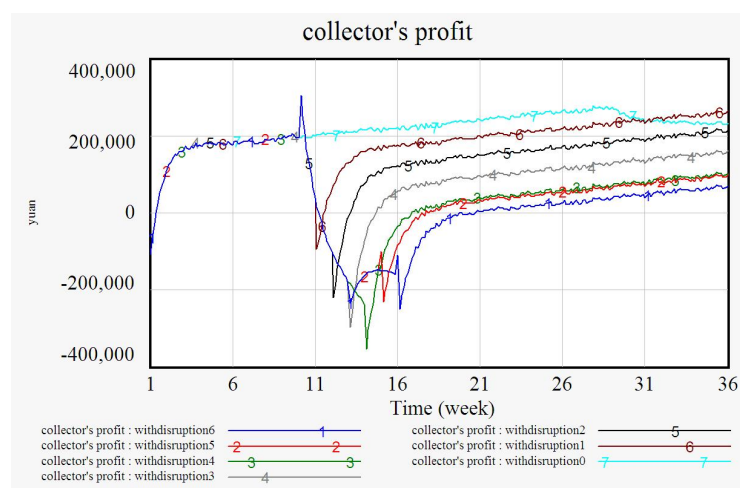

Figure 7 Collectors profits under different disruption periods (by using strategy)

If the strategy is ended, the collector's profit will increase quickly at the beginning and then have a decrease before continuously increasing again. The fluctuation of the collector's profit in Figure 7 looks like the curve of collector's profit at the beginning of the supply disruption in Figure 2.

Obviously, the collector can get more profit by using the strategy when a supply disruption lasts for more than 5 periods.

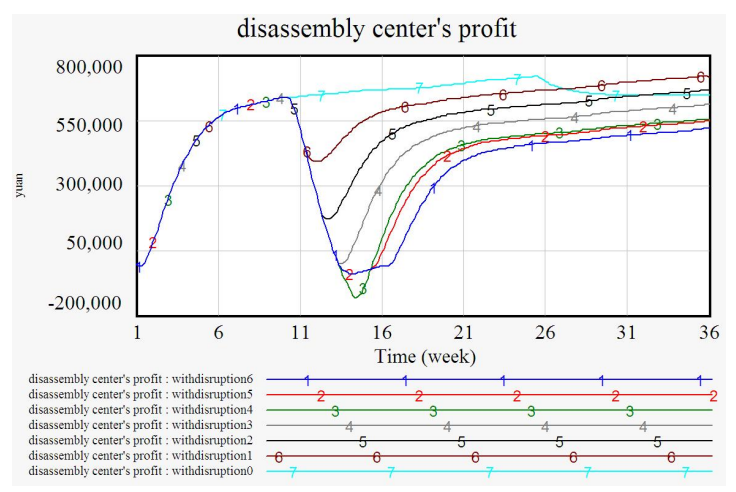

Figure 8 Disassembly centers profits under different disruption periods (by using strategy)

We can find how the strategy influences the profits of disassembly center and the remanufacturer, comparing the simulation results in Figure 8 (Figure 9) with the simulation results in Figure 3 (Figure 4).If the collector adopts the strategy when the supply disruption lasts for 5 periods (or 6 period), the disassembly center's profit (remanufacturer's profit) will increase

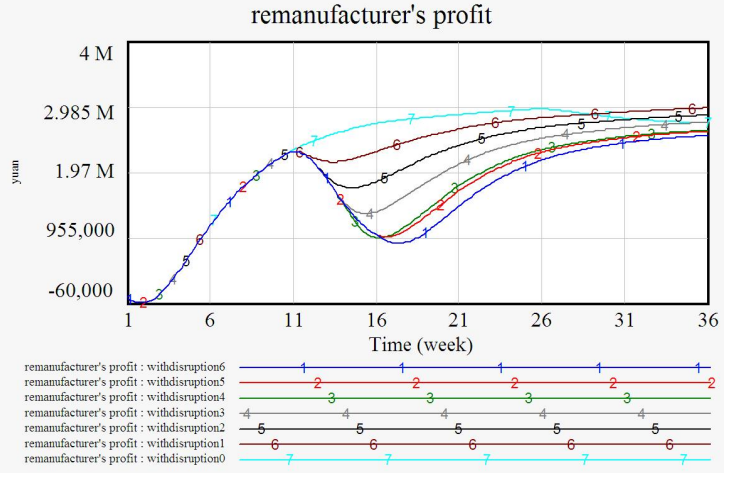

Figure 9 Remanufacturers profits under different disruption periods (by using strategy)

and will be higher than that in Figure 3 (Figure 4). Namely, the disassembly center and the remanufacturer can get more profits by using the strategy.

\subsubsection{Impacts of supply disruption on the mean of profit under the strategy}

From the Figure 7, Figure 8 and Figure 9, we can find the following fact. Even though the collector, the disassembly center and the remanufacturer can obtain more profits by adopting the strategy, in some period$\mathrm{s}$ the collector's profit, the disassembly center's profit and the remanufacturer's profit are negative. Therefore, we will show the mean of their profits after using the strategy in Figure 10.

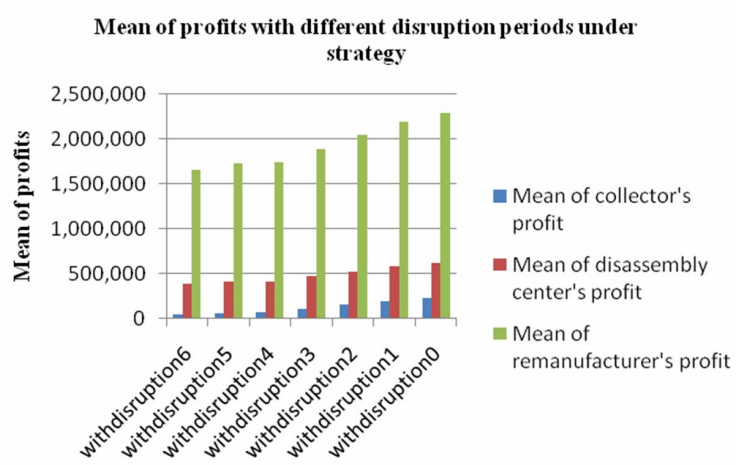

Figure 10 Mean of profits under different disruption periods (by using strategy)

Comparing the results in Figure 10 with the results in Figure 5, the following findings can be shown: The mean of the collector's profit, the mean of the disassembly center's profit and the mean of the remanufacturer's profit in Figure 10 are larger than that in Figure 5 respectively. Moreover, if the supply disruption last$\mathrm{s}$ for 5 or 6 periods, the mean of the collector's profit will be positive, which means the collector can get positive profit. 


\subsection{Impacts of purchase quantity on profits}

In the simulation of subsection 5.2.1 and subsection 5.2.2, purchase quantity is 2000 [Unit: piece]. However, purchase quantity will affect the reverse supply chain members profits. If purchase quantity is too small or too large, the collector may get negative profit even though purchasing used-products from other areas. Next, we will observe the impacts of purchase quantity on the profits via simulation with differen$\mathrm{t}$ value of purchase quantity. Our goal is to find a suitable range for purchase quantity to ensure the collectors positive profit.

The simulation results and the values of purchase quantity used in each simulation are presented in Table 1, Figure 11 and Figure 12. Herein, simulation situation withd6q500 means the supply disruption last$\mathrm{s}$ for 6 periods and purchase quantity is 500 pieces, withd6q45500 means the supply disruption lasts for 6 periods and purchase quantity is 45500 pieces, and so on.

The reason why we choose these values of purchase quantity $(500,820,830,900,1000,8000,9000,10000$, 11000 , 12000, 20000, 30000, 40000, 45000, 45100, 45500 ) is that we find some special points and we want to observe the changing around these points. For example, purchase quantity ranges from 830, 11000 to 45100 .

Table 1 Min, Max and Mean of collectors profit with different values of purchase quantity

\begin{tabular}{|c|c|c|c|}
\hline \multirow{2}{*}{$\begin{array}{c}\text { Simulation } \\
\text { situation }\end{array}$} & \multicolumn{3}{|c|}{ Collectors profit } \\
\cline { 2 - 4 } & Min & Max & Mean \\
\hline withd6q500 & -410559 & 305879 & -9529 \\
\hline withd6q820 & -376500 & 305879 & -203.80 \\
\hline withd6q830 & -375435 & 305879 & 87.17 \\
\hline withd6q900 & -367985 & 305879 & 2125 \\
\hline withd6q1000 & -357341 & 305879 & 5026 \\
\hline withd6q8000 & -385798 & 573525 & 181768 \\
\hline withd6q9000 & -410798 & 685996 & 201249 \\
\hline withd6q10000 & -435798 & 798351 & 209901 \\
\hline withd6q11000 & -460798 & 910625 & 211340 \\
\hline withd6q12000 & -485798 & 805050 & 206696 \\
\hline withd6q20000 & -685798 & 784914 & 159394 \\
\hline withd6q30000 & -935798 & 690296 & 96468 \\
\hline withd6q40000 & -1186000 & 520665 & 32671 \\
\hline withd6q45000 & -1311000 & 500001 & 666.03 \\
\hline withd6q45100 & -1313000 & 496602 & 23.80 \\
\hline withd6q45500 & -1323000 & 483005 & -2545 \\
\hline
\end{tabular}

In Table.1, the minimum, the maximum and the mean of collectors profit with different values of purchase quantity are listed. Figure.11 illustrates the mean of

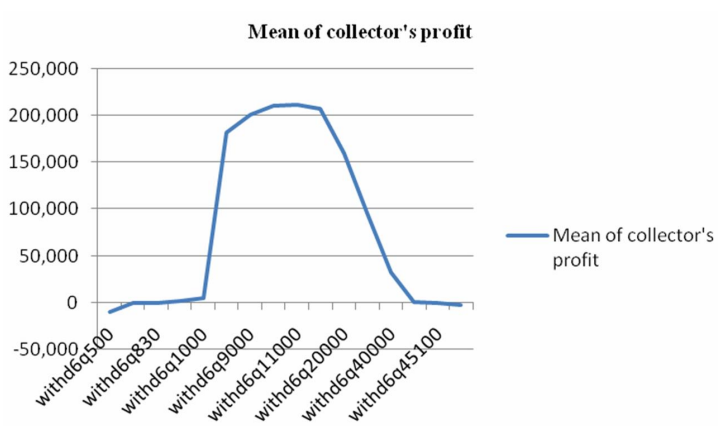

Figure 11 Mean of collectors profits with different purchase quantity (by using strategy)

collectors profits. From Table 1 and Figure.11, we can get the following findings:

The collector can get the highest mean of his profit if he purchases 11000 pieces of used-products.

If the purchase quantity of the used-products is little smaller than 830 pieces, the mean of collector's profit will be smaller than zero. It means the collector cant get the positive profit.

If the purchase quantity of the used-products is little larger than 45100 pieces, the mean of collector's profit will be smaller than zero, too. This is because in this situation the level of collectors inventory becomes higher and the holding cost becomes very high.

So, the suitable range of purchase quantity is from 830 (little less than 830) pieces to 45100 (little more than 45100) pieces.

In order to analyze the impacts of purchase quantity on the mean of disassembly centers profit and the mean of remanufactures profit, we show the relevan$\mathrm{t}$ simulation results in Figure 12. Figure.12 tells us: the mean of disassembly centers profit and the mean of remanufacturers profit will increase when purchase quantity of used-products increase, though at the end the increase is slow.

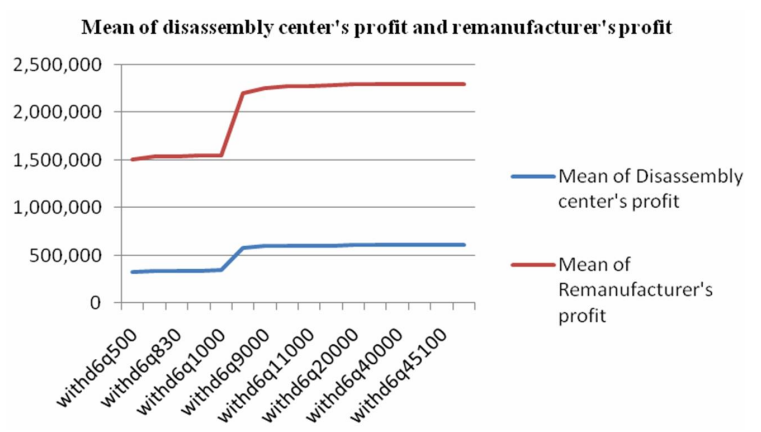

Figure 12 Remanufacturers profits under different disruption periods (by using strategy) 


\section{Conclusions}

The reverse supply chain under our study has four different supply disruptions. In this paper, we study the supply disruption of used-products between endconsumers and collector. Based on the expanded stockflow diagram with supply disruption of the reverse supply chain, we show the simulation results and give the analysis of the impacts of the supply disruption on the collector's profit, the disassembly center's profit and the remanufacturer's profit. By analyzing the simulation results, we find that the mean of the collector's profit will be approximate or smaller than zero if the supply disruption lasts for 5 or 6 periods. In order to manage the members profits, especially to ensure the collectors positive profit, we give a strategy, simulate and analyze the members profits after using the strategy, and show the suitable range of the purchase quantity of used-products. This simulation model and the results can help the members of the reverse supply chain make appropriate decisions to ensure positive profits under different supply disruption periods. The management of supply disruption of the $\mathrm{R} / \mathrm{M}$ integrated supply chain will be the further study area.

\section{Acknowledgments}

The authors would like to appreciate the National Nature Science Foundation of China under Grant No. 70871089.

\section{References}

[1] Q. L. Gu and T. G. Gao,"Managing Supply Disruption for Remanufacturer of Reverse Supply Chain", IEEE Int. Conf. on Service Operations and Logistics, and Informatics, pp.331-335, 2012.

[2] X. F. Shao,"Demand-side Reactive Strategies for Supply Disruptions in a Multiple-product System", Int. J. Prod. Econ., vol.136, pp.241-252, 2012.

[3] A. Sarkar and P.K.J. Mohapatra, "Determining the Optimal Size of Supply Base with the Consideration of Risks of Supply Disruptions", Int. J. Prod. Econ., vol.119, pp.122-135, 2009.

[4] J. Hou, A. Z. Zeng and L. Zhao, "Coordination with a Backup Supplier through Buy-back Contract under Supply Disruption", Transport. Res. E-log., vol.46, pp.881-895, 2010.

[5] A. Xanthopoulos, D. Vlachos and E. Iakovou, "Optimal newsvendor policies for dual-sourcing supply chains: A disruption risk management framework", Comput. Oper. Res., vol.39, pp.350-357, 2012.
[6] M. F. Huang, M. Y. Yang, Y. K. Zhang and B.Y. Liu, "System Dynamics Modeling-based Study of Contingent Sourcing under Supply Disruptions", Syst. Eng. Procedia, vol.4, pp.290-297, 2012.

[7] Q. L. Gu and T. G. Gao, "Simulation for disassembly planning of used-product in reverse supply chain", ICIC ELB, vol.2, pp.1315-1320, 2011.

[8] Q. L. Da, H. Sun and H. Zhou, "Simulation of remanufacturing in reverse supply chain based on system dynamics", Proc. 5th Int. Conf. Service Syst. and Service Manage - Exploring Service Dynamics with Science and Innovative Technology, pp.1-6,2008.

[9] Q. L. Gu and T.G. Gao, "System Dynamics Analysis of RFID/EPCs Impact on Reverse Supply Chain", Proc. Int. Conf. Manage. Sci. Eng., pp.250-255,2011.

[10] Q. L. Gu and T.G. Gao, "Joint decisions for R/M integrated supply chain using system dynamics methodology”, Int. J. Prod. Res., pp.1-18,2011.

[11] P. Georgiadis and M. Besiou, "Sustainability in electrical and electronic equipment closed-loop supply chains: A system dynamics approach", J. Clean. Prod.,vol. 16, pp.1665-1678,2008. 